\title{
Identifying key domains of health-related quality of life for patients with Chronic Obstructive Pulmonary Disease: the patient perspective
}

Muirne CS Paap ${ }^{1 *}$, Christina Bode ${ }^{2}$, Lonneke IM Lenferink ${ }^{3,4}$, Lianne C Groen ${ }^{3}$, Caroline B Terwee ${ }^{5}$, Sara Ahmed ${ }^{6}$, Owis Eilayyan ${ }^{7}$ and Job van der Palen ${ }^{1,8}$

\begin{abstract}
Background: Numerous instruments are available to measure health-related quality of life (HRQoL) in patients with Chronic Obstructive Pulmonary Disease (COPD), covering a wide array of domains ranging from symptoms such as dyspnea, cough and wheezing, to social and emotional functioning. Currently no information or guide is available yet to aid the selection of domains for a particular study or disease population. The aim of this paper is to identify which domains of HRQoL are most important with respect to COPD, from the patient perspective.

Methods: Twenty-one Dutch patients with COPD were asked to describe important domains impacted by COPD freely; second, they were presented with cues (domains from the Patient-Reported Outcomes Measurement Information System (PROMIS) framework) and were asked to select the domains that were most relevant to them. During the interview, the patients were asked to indicate in which way the selected domains impact their lives. Both the answers to the open question, and the patient statements motivating nomination of PROMIS domains were coded into themes.

Results: The most relevant (sub)domains of HRQOL for patients with COPD were: physical health (fatigue, physical functioning), social health (instrumental support, ability to participate in social roles and activities, companionship, and emotional support), and coping with COPD.

Conclusion: We identified which domains of HRQoL are most important to patients with COPD. One of these (coping with COPD) is not explicitly covered by PROMIS, or by traditional questionnaires that are used to measure HRQOL in COPD.
\end{abstract}

Keywords: HRQoL, COPD, Physical functioning, Physical health, Social health, Interview study, Qualitative research, PROMIS

\section{Background}

Chronic Obstructive Pulmonary Disease (COPD) is one of the leading causes for mortality worldwide [1]. COPD is characterized by dyspnea, chronic cough, sputum production, a decreased exercise performance and reduced physical activity level $[2,3]$. COPD cannot be cured; the main goal of COPD treatments is managing symptoms and their effect on the patient's health-related quality of

\footnotetext{
* Correspondence: m.c.s.paap@utwente.nl

'Department of Research Methodology, Measurement, and Data-Analysis, Behavioral Sciences, University of Twente, P.O. Box 217, 7500 AE Enschede, The Netherlands

Full list of author information is available at the end of the article
}

life (HRQoL) [3]. Consequently, HRQoL has become an important outcome measure in COPD research and clinical care.

HRQoL encompasses the physical, functional, emotional, and social well-being of the patient [4]. HRQoL is a highly subjective experience by definition and therefore measured by self-report questionnaires (patient reported outcome measures; PROMs). Many questionnaires are available to measure HRQOL in patients with COPD, covering a wide array of domains ranging from symptoms such as dyspnea, cough and wheezing, to social and emotional functioning (see [5] for an overview), and it can be a challenge to choose the appropriate questionnaire. 
Aspects to consider include domain coverage, test length (e.g. [6,7]), recall period (for example, last year or last few weeks), the interpretation of (change in) scores, psychometric properties (e.g. [8]), and whether it is generic or disease-specific, among other things [9]. Since both generic and disease-specific instruments have desirable properties, several researchers advocate using both types of instruments to assess HRQoL in patients with COPD $[10,11]$. Generic instruments can be used with any (patient) population, facilitating direct comparison among populations, including the general population. Diseasespecific instruments are developed for a specific patient population, which may increase the sensitivity to measure intra-individual change after an intervention. However, clinicians tend to prefer short instruments for use in clinical practice, so the test battery should not be too lengthy. Unfortunately, short instruments often fail to provide a sufficiently detailed picture of the most relevant aspects of a patient's HRQoL.

In recent years, Computerized Adaptive Testing (CAT) [12] based on Item Response Theory (IRT) [13] has been put forward as a possible solution to the dilemma. A CAT is a digital questionnaire tailored to the individual patient, resulting in each item (question) contributing valuable information, while maintaining comparability across patients. Item selection in a CAT is dependent on a patient's response to previous items. In this way the latent trait estimate is continuously adjusted, until a specific level of measurement precision (reliability) is reached. In recent years, a large number of IRT-calibrated item banks have been developed to measure domains of HRQoL. This initiative is referred to as "PROMIS" (Patient Reported Outcomes Measurement Information System) [14], and resulted in item banks covering physical, mental, and social health. Both CATs and short forms have been developed using the item banks [15]. The PROMIS banks are generic, and have been calibrated using a large sample from the general population as well as subsamples of numerous patient groups, including COPD. However, it is still up to the user to decide which domains to select.

Since HRQoL is a highly subjective experience, it is not only paramount to use PROMs to measure it, but also to involve patients in the development and selection process of PROMs. It has been repeatedly shown that taking patient perspective into account during PROM development allows for the identification of problems with item content and coverage as well as problems with domain coverage and/or poor operationalization (e.g., [16-27]). These findings have inspired several guidelines concerning the development of PROMs. The European Organisation for Research and Treatment of Cancer (EORTQ) even proposes that patient perspective should be leading when "...compiling an exhaustive list of relevant QoL issues that cover the domain(s) of interest" [28]. Within the PROMIS framework, patient perspective has played an important role in item bank development [29-32]. Focus-groups were used to evaluate item content, coverage and wording, as well as the content validity of the item banks by evaluating the fit between the domain map that was drafted by a panel of experts, and concepts that focus-group participants identified as important aspects of HRQoL [33-36]. It should be noted that in this set-up, feedback from experts was used to conceptualize a domain-map, and subsequently input from patients (responding to open questions) was used to verify the domain map. Patients were not explicitly asked to comment on the domain-map, or to choose domains themselves.

Currently, there is no consensus as to which instruments are most appropriate to assess HRQoL in COPD patients. However, it has been argued that combining generic and disease-specific measures may provide the most useful estimations. PROMIS is probably the best generic instrument that is currently available to measure HRQoL; it consists of a wide range of generic item banks that have been developed with a rigorous and sound methodology. However, no core sets or recommendations are available to guide the selection process of PROMIS item banks for use with COPD patients (or any disease group for that matter); nor is it clear whether all domains relevant for COPD are covered by current PROMIS item banks. In line with aforementioned guidelines and published studies, we agree the patient perspective should play an important role in domain selection and assessment of domain coverage. The aim of this paper is to identify which domains of HRQoL are most important from the COPD patient's perspective, and why. We will do this in two steps: first patients are asked to describe important domains freely; second, they are presented with PROMIS domains and are asked to select those most relevant to them. The patient is invited to explain the motives behind their choice, providing insight in the way they conceptualize and experience HRQoL. The results of this study can be used to inform instrument selection and development. This study is the first of an international collaboration (the Netherlands and Canada) that involve two research groups following the same steps (Additional file 1) to create a CAT to measure HRQoL in COPD patients.

\section{Methods}

\section{Context of the study}

This exploratory study was initiated in order to establish which domains of HRQoL are most relevant to patients with COPD. MP and JP acquired funding from the Dutch Lung Foundation in order to develop a new instrument to measure HRQoL in patients with COPD. However, at present no guidelines are available that can aid an interested party to select appropriate domains for their purpose 
(e.g., instrument development, clinical trial, clinical evaluation); this applies to PROMIS domains as well as legacy instruments. Therefore, MP and JP decided to start their project by conducting an interview study. $\mathrm{CB}$ was involved as an expert in qualitative research and patient perspective, and CT was involved because of her affiliation with the PROMIS initiative, as well as her methodological expertise. SA and OE were involved since they had the same goals as MP and JP; it was decided that an international collaboration would increase the overall value and impact of the project. Due to time constraints, it was decided that the interview study would be executed in the Netherlands first. The drafting of the framework was a joint effort. The interview scheme used in this study was translated into English and will be used in a future study to validate the findings of the current study in Canada.

\section{Patients}

The target population consisted of COPD patients seeking treatment. We engaged two pulmonary clinics that assisted in recruiting patients: Medisch Spectrum Twente hospital, Enschede (the Netherlands) and the Sint Franciscus Gasthuis hospital, Rotterdam (the Netherlands). The patients were invited to participate in the interview study by their pulmonologists. The only inclusion criterion was a diagnosis of COPD. If the patients agreed to participate, they were taken to a quiet hospital room where the interviewer explained the study in more detail, and presented the patients with an informed consent form before starting the interview. Consecutive patients who had appointments with their pulmonologists in March and April 2013 were considered for inclusion. Purposive sampling was used, aimed at maximum obtainable variation with regard to patient characteristics, including gender, age and GOLD stage (I\&II and III\&IV). Inclusion stopped when saturation was reached.

\section{Interview}

The interview was semi-structured (see Additional file 2 for the interview scheme). The focus was assessing how COPD impacts HRQoL from the patient's perspective. The interview scheme consisted of two parts: an open question, and a card sorting task. First, patients were asked: "In what way does your COPD influence your quality of life?" Next, participants were presented with 16 PROMIS domains [37] printed on separate cards, along with three randomly chosen example items from that domain (see Additional file 3). The patients were invited to select and rank the five domains that were the most relevant to them with regards to their COPD. Patients were asked to think aloud while making this selection, and elaborate on their choices. Each interview was recorded and transcribed verbatim.

At the time of the interview, Dutch translations of 17 PROMIS domains were available. We chose not to use the domain "global health" since we wanted to know what specific domains of HRQoL were most relevant from the patient's perspective. We felt that ranking all 16 domains would be too challenging, so we decided to divide the task in two parts: first the most important domains were chosen, and then these were ranked. Previous research has shown that rating and ranking five domains is a doable task [38], so patients were asked to select and rank five domains.

\section{Ethics}

The ethical review board of the University of Twente approved the study. All patients gave informed consent. This study did not need approval of the Medical Ethical Review Board, according to European regulations.

\section{Data analysis}

The interviews were held and transcribed by a trained interviewer (LG). Patients' statements were coded and interpreted by hand, and the number of times a domain was chosen was counted. After choosing the domains, the patients were asked to rank order these domains from most relevant to least relevant, but not all patients followed the instructions. Some patients chose fewer or more than five domains, and some said they could not rank them because they felt all were equally (un)important. We therefore decided to not include the rank orders of the domains in the analysis.

Coding was performed in several steps by two raters (LG and LL). The coding process was supervised by $\mathrm{CB}$ and MP. LG and LL first coded the interviews on their own, after which several consensus meetings took place. In challenging cases, MP was involved in the consensus process. The open question and PROMIS card sorting task were analysed separately, yet the same coding procedure was used. Prior to coding, irrelevant interview passages (spontaneous statements that do not concern the research question) were removed. We used two types of coding strategies described in grounded theory research: open and axial coding [39]. When using open coding, the data are broken down into units (events, actions, interactions, emotions) that are assigned conceptual labels, so they can be grouped together into themes. Meaningful units constitute parts of a sentence, a whole sentence, or a passage of text that pertains to the same topic. A meaningful unit has to be long enough (contain enough information) to allow meaningful interpretation with respect to the research question and the theme with which it is associated. When using axial coding, units are related to themes and subthemes. In our study, this process was facilitated by what we refer to as interpretations of meaningful units (Table 1). For example, the unit "When I have to walk up and down the stairs, I move up the stairs in a sitting position and then I'm very short of breath" was interpreted in the following way: "Going up the stairs is a difficult and laborious 
Table 1 Examples showing how units were interpreted and coded into themes for answers given to the open question

\begin{tabular}{llll}
\hline Main theme & Sub-theme & Selected unit & Interpretation \\
\hline Physical health & $\begin{array}{l}\text { Light physical activity } \\
\text { causes physical complaints }\end{array}$ & $\begin{array}{l}\text { "When I have to walk up and down the stairs, I move } \\
\text { up the stairs in a sitting position and then I'm very } \\
\text { short of breath." }\end{array}$ & $\begin{array}{l}\text { Going up the stairs is a difficult and laborious } \\
\text { exercise, which causes shortness of breath. }\end{array}$ \\
\hline Physical health & $\begin{array}{l}\text { Heavy physical activity } \\
\text { causes physical symptoms }\end{array}$ & $\begin{array}{l}\text { "Especially, during heavy physical exertions, you feel } \\
\text { some pain at times, and you experience some } \\
\text { shortness of breath." }\end{array}$ & $\begin{array}{l}\text { Heavy physical exertion triggers pain and } \\
\text { shortness of breath. }\end{array}$ \\
\hline Physical health & Stamina & $\begin{array}{l}\text { "My stamina is, of course, somewhat lower than others. } \\
\text { I think that is actually the most important point." }\end{array}$ & Stamina is lower in comparison to others. \\
\hline Autonomy & Asking for help & "Now I have to ask others can you please help me? & It is difficult to ask others for help. \\
\hline Autonomy & Independence & "Then I get irritable, because I like to do everything & Loss of independence causes anger. \\
& & myself, and I'm not able to do that." &
\end{tabular}

exercise, which causes shortness of breath." This unit was subsequently placed in the sub-theme "Light physical activity causes physical complaints", which was associated with the main theme "Physical health". The main themes physical health and autonomy which emerged from the open question, and the PROMIS domains fatigue and ability to participate in social roles and activities were chosen to illustrate the coding process (Tables 1 and 2, respectively).

\section{Results}

Twenty-one COPD patients (13 men; mean age 66.1 $(\mathrm{SD}=9.3)$ years $)$ were included; $24 \%$ of them were recruited in Rotterdam; 19\% were inpatients; 9.5\% had GOLD stage I, 38\% GOLD stage II, 43\% GOLD stage III, and 9.5\% GOLD stage IV. The face-to-face interviews took 15-30 minutes. See Table 3 for descriptive characteristics for each patient.

\section{Open question: "In what way does your COPD influence your quality of life?"}

Table 4 presents the main themes that emerged from the analysis of the open question, along with sub-themes. Below, all main themes that emerged from the answers given by more than one patient are briefly discussed; for some themes, patient quotes are given.

Of the ten main themes, two were by far the most popular: physical health and coping with COPD-related complaints. Patients described that light physical activities, such as walking, climbing the stairs and doing household chores, trigger physical complaints. Decline of stamina, restrictions in general physical activity and invalidity were the next most common subthemes of physical health (see Table 1 for examples). Some patients indicated that the impact of their COPD on their physical activity fluctuated.

"There is a tram stop nearby... walking that distance...sometimes I can manage it, sometimes I can't." (ID 1)
Used coping strategies were: doing only as much as they could or trying to avoid activities that could lead to dyspnoea, and performing short bouts of light to moderate intensity activities in order to maintain a balance between rest and activity.

"You do your household chores as best as you can, but you also take a lot of rest breaks. In that way you're able to cope with it." (ID 6)

Some patients experienced limitations regarding hobbies and leisure time. Autonomy was mentioned several times; patients reported that it is difficult and frustrating to be dependent upon others (see Table 1 for examples). For some patients, their social lives changed negatively due to COPD. Anxiety or fear of suffocation was also experienced by some.

"And then I was at home alone and then I screamed for help: I thought I was going to suffocate. The feeling just wouldn't pass." (ID 5)

\section{Selecting the most relevant PROMIS domains}

The card sorting method produced results on the relative importance of the PROMIS domains (Figure 1). The statements that the patients gave when motivating their choice of domains were coded into themes. In Table 5, all main themes are listed by PROMIS domain.

The three most frequently chosen domains were instrumental support, fatigue and ability to participate in social roles and activities. Instrumental support was relevant for patients because they need help or assistance due to their physical constraints.

"Luckily, I have a domestic help, and if I hadn't had that kind of help nothing would have gotten done..." (ID16) 
Table 2 Examples showing how units were interpreted and coded into themes for two PROMIS domains

\begin{tabular}{|c|c|c|c|c|}
\hline Selected domain & Main theme & Sub theme & Selected unit & Interpretation \\
\hline Fatigue & Coping with fatigue & Rest & $\begin{array}{l}\text { "When I'm at home and I'm tired, I } \\
\text { really can't be bothered with } \\
\text { anything, the whole world may be } \\
\text { turned upside down for all I care, all } \\
\text { I want is to lie down." }\end{array}$ & $\begin{array}{l}\text { Lying down as a reaction to } \\
\text { fatigue. }\end{array}$ \\
\hline Fatigue & Effects of fatigue & $\begin{array}{l}\text { Downward performance } \\
\text { spiral of fatigue: fatigue } \\
\text { leads to activity restrictions. } \\
\text { Activities trigger breathing } \\
\text { difficulties. }\end{array}$ & $\begin{array}{l}\text { "Yes, you get tired more quickly. } \\
\text { You've also got the feeling that if you } \\
\text { want to do something...then you ask } \\
\text { yourself right away should I do that or } \\
\text { how should I go about it so that I } \\
\text { won't suffer breathing problems." }\end{array}$ & $\begin{array}{l}\text { Activity limitations due to } \\
\text { fatigue, and activities trigger } \\
\text { breathing problems. }\end{array}$ \\
\hline Fatigue & $\begin{array}{l}\text { Determinants of } \\
\text { fatigue }\end{array}$ & $\begin{array}{l}\text { Combination of work and } \\
\text { medicines lead to fatigue. }\end{array}$ & $\begin{array}{l}\text { "I'm always tired anyway, if I didn't } \\
\text { have to go to work I would be tired } \\
\text { all the same, you actually get tired } \\
\text { because of the medicines you have } \\
\text { to take during the day. One } \\
\text { medicine has to widen the blood } \\
\text { vessels, the other has to narrow } \\
\text { them again ... it's a combination of } \\
\text { (the aforementioned)." }\end{array}$ & $\begin{array}{l}\text { Combination of work and } \\
\text { medicines lead to severe fatigue. }\end{array}$ \\
\hline $\begin{array}{l}\text { Ability to participate } \\
\text { in social roles and } \\
\text { activities }\end{array}$ & $\begin{array}{l}\text { Determinants of } \\
\text { ability to participate } \\
\text { in social roles and } \\
\text { activities }\end{array}$ & Mobility restrictions & $\begin{array}{l}\text { "Because of your shortness of } \\
\text { breath you are restricted in your } \\
\text { mobility and therefore also in your } \\
\text { social roles. A while ago, I was } \\
\text { supposed to attend a funeral at } \\
\text { XX...that's a problem." }\end{array}$ & $\begin{array}{l}\text { Symptoms cause mobility } \\
\text { restrictions as a result of which } \\
\text { social contacts are not possible } \\
\text { which in turn leads to limitation } \\
\text { in social roles. }\end{array}$ \\
\hline $\begin{array}{l}\text { Ability to participate } \\
\text { in social roles and } \\
\text { activities }\end{array}$ & Hobby/Leisure time & $\begin{array}{l}\text { Limitation in social role at } \\
\text { sports club }\end{array}$ & $\begin{array}{l}\text { "I used to be the leader of a football } \\
\text { team, and I could run as fast as the } \\
\text { boys, but those days are over." }\end{array}$ & $\begin{array}{l}\text { Quit participation in social role } \\
\text { and sports activity }\end{array}$ \\
\hline \multirow{2}{*}{$\begin{array}{l}\text { Ability to participate } \\
\text { in social roles and } \\
\text { activities }\end{array}$} & \multirow[t]{2}{*}{ Hobby/Leisure time } & \multirow[t]{2}{*}{$\begin{array}{l}\text { Limitation during sports } \\
\text { activity }\end{array}$} & $\begin{array}{l}\text { "You have to limit it somewhat, } \\
\text { don't you? }\end{array}$ & \multirow[t]{2}{*}{$\begin{array}{l}\text { Limitation in degree of physical } \\
\text { activity during sports activity }\end{array}$} \\
\hline & & & $\begin{array}{l}\text { When I go swimming, for instance, I } \\
\text { bring two people; well, those two are } \\
\text { able to swim very well, when they } \\
\text { have reached the other side of the } \\
\text { pool for the second time, I have yet to } \\
\text { reach the other side for the first time." }\end{array}$ & \\
\hline
\end{tabular}

In contrast, some patients indicated that they had trouble accepting help from others, and had to employ coping strategies to deal with this change in dependency.

Patients described fatigue as highly bothersome in various ways; a chronic lack of energy, feeling already totally exhausted when waking up or experiencing feelings of weariness, etc. The most frequently mentioned way to cope with fatigue was to lie down and rest. Patients were not always very clear on determinants of fatigue: it could occur without any reason, or result from physical activity or use of medication. See Table 2 for quotes. Patients associated ability to participate in social roles and activities primarily with hobbies and leisure time. They experienced restrictions in physical activities during holidays; for example, climbing stairs of a tower or hiking. Some described adjusting the intensity of sports activities and avoiding social activities. See Table 2 for more examples.

The next three most frequently chosen domains were companionship, physical function and emotional support.
Companionship was described in terms of how content patients were with the companionship of others. Most statements consisted of summing up the social contacts, e.g. children, partner and grandchildren. Physical function was described as being restricted in daily life tasks, such as dressing, climbing stairs and vacuum cleaning. A few patients described themselves as physically disabled. Autonomy was another reported main theme.

\section{"The feeling of powerlessness, that for everything you have always to rely on others to help you, that is annoying." (ID 5)}

Emotional support was relevant because patients have the need to talk to someone to be comforted, to vent their feelings, to discuss problems or ask for advice. Partners and children are the most favoured persons patients confide in. Some stated that talking to someone is 'healing', it prevents emotional problems from getting worse and it improves mood. 
Table 3 Patient characteristics

\begin{tabular}{|c|c|c|c|c|c|c|}
\hline ID & Gender & Age & GOLD stage & Location & Outpatient/inpatient & Comorbidity \\
\hline 1 & M & 58 & III & $\mathrm{R}$ & Outpatient & Yes \\
\hline 2 & M & 78 & III & $\mathrm{R}$ & Outpatient & Yes \\
\hline 3 & M & 67 & $\|$ & $\mathrm{R}$ & Outpatient & Yes \\
\hline 4 & M & 72 & III & $\mathrm{R}$ & Outpatient & Yes \\
\hline 5 & M & 76 & IV & $\mathrm{R}$ & Outpatient & Yes \\
\hline 6 & $\mathrm{~F}$ & 66 & III & $\mathrm{E}$ & Outpatient & No \\
\hline 7 & M & 68 & III & $\mathrm{E}$ & Inpatient & No \\
\hline 8 & M & 52 & 1 & $E$ & Outpatient & Yes \\
\hline 9 & M & 63 & III & $E$ & Outpatient & Yes \\
\hline 10 & M & 52 & $\|$ & $\mathrm{E}$ & Outpatient & Yes \\
\hline 11 & M & 54 & $\|$ & $E$ & Outpatient & Yes \\
\hline 12 & $\mathrm{~F}$ & 58 & $\|$ & $E$ & Outpatient & Yes \\
\hline 13 & $\mathrm{~F}$ & 69 & $\|$ & $\mathrm{E}$ & Outpatient & No \\
\hline 14 & $\mathrm{~F}$ & 67 & III & $E$ & Outpatient & Yes \\
\hline 15 & $\mathrm{~F}$ & 81 & ॥ & E & Outpatient & Yes \\
\hline 16 & $\mathrm{~F}$ & 62 & IV & $E$ & Outpatient & Yes \\
\hline 17 & M & 73 & ॥ & $\mathrm{E}$ & Outpatient & Yes \\
\hline 18 & $\mathrm{~F}$ & 51 & ॥ & $E$ & Outpatient & Yes \\
\hline 19 & M & 84 & I & $E$ & Inpatient & Yes \\
\hline 20 & M & 70 & III & $E$ & Inpatient & Yes \\
\hline 21 & $\mathrm{~F}$ & 67 & III & $E$ & Inpatient & No \\
\hline
\end{tabular}

Location: $\mathrm{R}=$ Rotterdam, $\mathrm{E}=$ Enschede.

\section{Additional notable results}

Not one patient explicitly chose the domain depression, even though this theme emerged several times during the interviews in connection with other domains or themes. Feelings of depression were associated with fatigue, autonomy and acute exacerbations of COPD.

"And fatigue, sometimes I'm exhausted and I feel depressed and I think heck, why can't I do that, but there are also moments when I like it and don't at all resent it. It's so difficult." (ID 5)

A few patients expressed fear of suffocating associated with respiratory distress, which lead to thoughts of wanting to die or not minding to die.

"When it is so bad and stays so bad then I just hope it will be over." (ID 7)

Strikingly, the topic of autonomy was frequently mentioned in conjunction with various domains (see Table 5). Patients mentioned having trouble accepting help from others or that they avoid asking help from others. They get frustrated, angry or depressed when they are unable to do the things they want (independently). Losing one's autonomy is a struggle for patients.

"I'd like to do it more often but that isn't possible. Domestic help, for instance...terrible. But on the other hand I also think: my house is clean. Everything spic and span. But it vexes me, that I can't do it myself." (ID 12)

\section{Discussion}

Physical health and social health emerged as important overarching themes, while domains associated with mental health were hardly chosen or mentioned. Physical health emerged as the most important theme from the spontaneous statements that patients made when asked about HRQoL in relation to COPD, while two of the six most frequently chosen PROMIS domains (fatigue and physical functioning) pertain to the overarching domain of physical health [40]. Coping with COPD emerged as the second most important theme from the spontaneous statements, while the remaining four PROMIS domains pertained to social health (instrumental support, ability to participate in social roles and activities, companionship, and emotional support) [40]. In addition to the obvious overlap between the outcomes of the open question and the card 
Table 4 Overview of main themes and sub-themes connected to the open question

Main themes (number of occurrences)

Physical health (22)

\section{Sub-themes (number of occurrences)}

Light physical activity triggers physical complaints (6)

Stamina (4)

Fluctuating character of COPD (4)

Restriction in general physical activity (3)

Invalidity (2)

Restriction in physical functioning due to physical symptoms (1)

Heavy physical activity causes physical complaints (1)

Mobility (1)

Coping with COPD-related complaints/restrictions (9) Avoiding activities (3)

Balance between rest and activity (3)

Performing physical activities in order to avoid sitting at home (1)

Adapting activities (1)

Professional help for anxiety (1)

Hobby/Leisure time (3)

Going out (1)

Holidays (1)

Sport (1)

Asking for help (1)

Independence (1)

Fear of being alone (1)

Fear of suffocating (1)

Homebound (1)

Offering help to others (1)

Weather conditions (1)

Additional factors affecting symptoms (1)

Tired (1)

Fatigue (1)

Frustration (1)

Work (1)

Losing one's job (1)

Examples of light physical activity are walking up and down the stairs. Examples of heavy physi when the respondent did not give details.

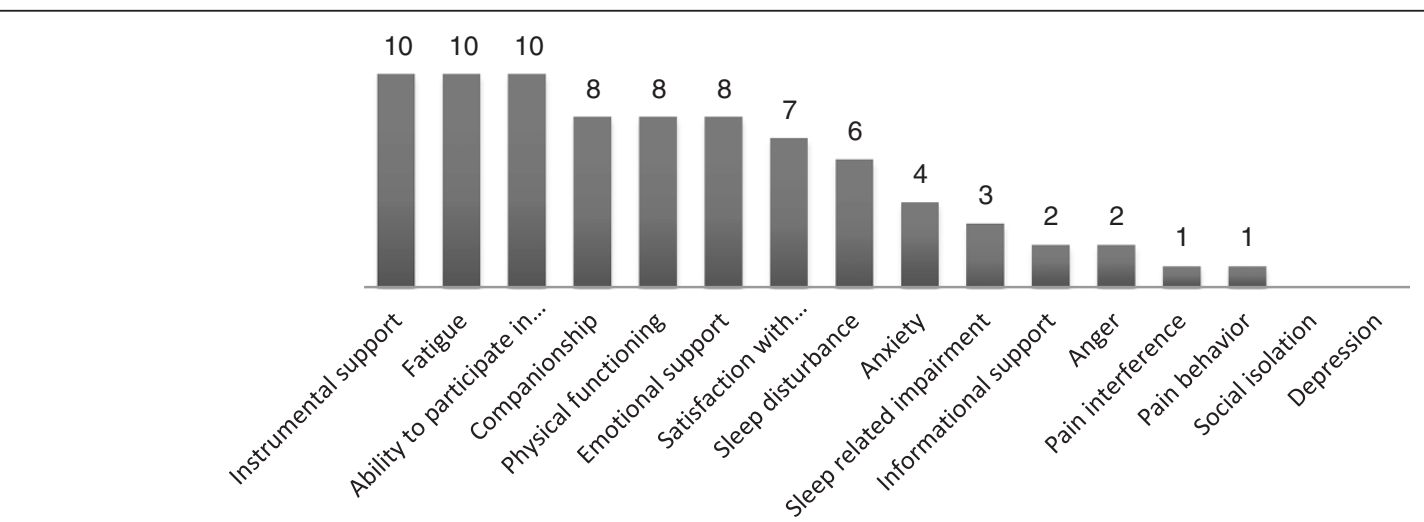

Figure 1 Number of times PROMIS-domains were selected. Note. Ability to part. in soc. roles and act = ability to participate in social roles and activities; Satisfaction with part. in soc. roles and act. = satisfaction with participation in social roles and activities. The patients were instructed to select the five most relevant domains, but twelve patients chose fewer than five domains (four domains $n=5$, three domains $n=3$, zero domains $n=4$ ) and four patients chose more than five domains (six domains $n=3$, eight domains $n=2$ ). 
Table 5 Overview of main themes derived from patient statements associated with the selected PROMIS domain

\begin{tabular}{|c|c|c|}
\hline Selected domain & Main themes & $\mathrm{N}^{*}$ \\
\hline \multirow[t]{4}{*}{ Instrumental support } & Description of instrumental support & 11 \\
\hline & Autonomy & 2 \\
\hline & Coping with instrumental support & 2 \\
\hline & Level of importance of instrumental support & 2 \\
\hline \multirow[t]{7}{*}{ Fatigue } & Description of fatigue & 6 \\
\hline & Coping with fatigue & 4 \\
\hline & Determinants of fatigue & 3 \\
\hline & Consequences of fatigue & 2 \\
\hline & Physical activity & 1 \\
\hline & Comorbidity leads to misconception & 1 \\
\hline & Mobility & 1 \\
\hline \multirow[t]{6}{*}{ Ability to participate in social roles and activities } & Hobby/Leisure time & 6 \\
\hline & Coping with limitations in the ability to participate in social roles and activities & 3 \\
\hline & Determinants of the ability to participate in social roles and activities & 2 \\
\hline & Restrictions in physical activities & 1 \\
\hline & Description of social roles and activities & 1 \\
\hline & Level of importance of social roles and activities & 1 \\
\hline \multirow[t]{7}{*}{ Companionship } & Description social contacts & 10 \\
\hline & Pointing out positive results of social contacts & 3 \\
\hline & Importance of social contacts & 3 \\
\hline & Description social activities & 1 \\
\hline & Level of satisfaction with company & 1 \\
\hline & Pointing out negative results of social contacts & 1 \\
\hline & Life and death & 1 \\
\hline \multirow[t]{5}{*}{ Physical function } & Experiencing limitation or complaints during physical exertion & 8 \\
\hline & Autonomy & 2 \\
\hline & Additional factors affecting physical complaints & 1 \\
\hline & Fatigue & 1 \\
\hline & Level of satisfaction with physical function & 1 \\
\hline \multirow[t]{3}{*}{ Emotional support } & Description of emotional support & 8 \\
\hline & Level of importance of emotional support & 2 \\
\hline & Pointing out positive results of emotional support & 2 \\
\hline \multirow[t]{3}{*}{ Sleep disturbance } & Description of sleep disturbance & 5 \\
\hline & Determinants of fatigue & 1 \\
\hline & Consequences of stress & 1 \\
\hline \multirow[t]{3}{*}{ Sleep related impairment } & Coping with problems caused by sleep disturbances & 2 \\
\hline & Description of problems caused by sleep disturbances & 1 \\
\hline & Comorbidity leads to misconception & 1 \\
\hline \multirow[t]{7}{*}{ Satisfaction with participation in social roles and activities } & Autonomy & 8 \\
\hline & Social life & 1 \\
\hline & Description of attitude to life & 1 \\
\hline & Determinants of fatigue & 1 \\
\hline & Consequences of fatigue & 1 \\
\hline & Anger & 1 \\
\hline & Level of importance of being independent from others & 1 \\
\hline
\end{tabular}


Table 5 Overview of main themes derived from patient statements associated with the selected PROMIS domain (Continued)

\begin{tabular}{lll}
\hline Informational support & Description of informational support & 3 \\
\hline Anxiety & Description of anxiety & 4 \\
\hline Pain interference & Consequences of physical complaints & 1 \\
\hline Pain behaviour & Description of pain & 1 \\
\hline Anger & Description of limitations due to pain & 1 \\
& Comorbidity leads to misconception & 2 \\
& Determinants of anger & 1 \\
& Coping with anger & 1 \\
& Importance of coping with anger & 1 \\
\hline
\end{tabular}

${ }^{*} \mathrm{~N}=$ number of occurences.

For each selected PROMIS-domain the units were interpreted and coded into main and sub themes. Only the main themes are presented in this table.

sorting task (PROMIS domains) with respect to physical health, there is a more subtle overlap with respect to coping. Analysis of the statements patients made to explain their choice of PROMIS domains, showed that coping was a frequently mentioned theme for three of the six most popular PROMIS domains. It should be noted that the statements elicited by the cues (PROMIS domains) were far richer in content than the spontaneous statements, providing us with a lot of information on the patients' perspectives on these different domains of HRQoL. However, the open question elicited highly valuable information as well, since patients were free to describe HRQoL in their own words; this resulted in an important main theme (coping with COPD) that is not explicitly covered by any of the existing PROMIS domains. These findings underline the importance of using a funnelshaped questioning strategy, as recommended by Brod and colleagues [27].

Surprisingly, very few patients mentioned or chose domains pertaining to mental health; only two patients mentioned anxiety when answering the open question, while one patient mentioned anger. During the card sorting task, four patients chose the PROMIS domain anxiety, and two patients chose anger. The PROMIS domain depression was not chosen by a single patient. These findings are striking, since the literature indicates that the prevalence of depression or the level of depressive symptoms is much higher in patients with COPD than in the general population; and also anxiety has been shown to be a serious problem in COPD [41-46]. Depression is still a taboo-subject for many; especially elderly people have been found to underreport depressive symptoms [47]. It should be noted, though, that although depression was not explicitly chosen, depressive feelings were mentioned by some patients in relation to fatigue, autonomy and acute exacerbations. The interviewed patients may have felt a bit daunted when confronted with the word directly.
Additionally, many COPD patients are plagued by feelings of guilt [48], knowing that they are at least partly responsible for the onset of their disease (tobacco smoking). As a result they may feel the need to keep a stiff upper lip, believing they have no 'right' to complain, resulting in an underreporting of psychological distress. We discussed this point with a number of COPD experts (researchers and pulmonologists), and several of them pointed out that it requires quite some probing in an interview/consultation to get the patients to open up about their depressive feelings. We therefore presume that the patients not choosing depression may have been a method-effect, and it cannot be ruled out that this domain is in fact relevant to patients with COPD. When it comes to anxiety, Strang and colleagues [46] found that patients experienced high levels of anxiety related to COPD symptoms, mostly in connection with the themes death anxiety (fear of suffocation, awareness of death, fear of dying, separation anxiety) and life anxiety (fear of living, fear of the future). Furthermore, patients also talked about coping strategies they used to deal with the feeling of suffocation, or fear of dying. In their study, Strang and colleagues started with a very general question ("Can you describe what living with COPD means to you?"), but continued with probing questions, including "What are your experiences of anxiety?" Their asking about anxiety directly may partly explain the differences between the results of our open question and their findings. When comparing these anxiety-related themes to the PROMIS anxiety item bank, it becomes apparent that the PROMIS anxiety items are formulated in a very general way. This may be an explanation as to why only few patients in this study chose this domain. It may make more sense to include disease-specific anxiety items that are directly related to COPD symptoms (such as shortness of breath) in an instrument that aims to measure HRQoL in COPD patients, rather than using the PROMIS anxiety domain. 
When comparing the most important themes and domains that emerged in this study, to domains covered by the most frequently used instruments to assess HRQoL in COPD [5], a few things stand out. Among the domains most frequently covered by existing instruments are energy/fatigue and social functioning; our findings clearly show support for these being important domains from the patient perspective. However, although many existing instruments focus at least in part on COPD symptoms (dyspnea, cough, phlegm, chest tightness), only few focus on the impact of COPD on daily life [5]. Our results show that this is an important shortcoming of the existing instruments, as many patients indicated they struggle with the impact of COPD on daily activities, as well as finding a way to cope with this negative impact. Most patients indicated that physical activity triggers or aggravates their symptoms, and several patients indicated that they have to avoid or adapt their daily activities. For some patients, these limitations were so severe that they considered themselves as invalids. Many patients struggle daily with their dependency on others in performing daily life tasks; they feel ashamed and frustrated that they are no longer selfreliant.

It should be noted that some patients found it difficult or refused to follow the instructions. Four patients did not pick any PROMIS domain. They argued that they were in good physical shape or were at least able to do everything they wanted; or they fully accepted the consequences of COPD and were able to adjust to it. It may be that the PROMIS domains were too general, which could be solved by adding a disease-specific module to the PROMIS domain framework. Some patients had comorbid disorders and indicated that it was difficult for them to identify the exact impact of COPD. Other patients attributed part of the symptoms that impacted their HRQoL to the 'normal' ageing process. Some patients had trouble to pick exactly five important domains. Patients that picked fewer than five domains indicated that they had trouble seeing the difference among some of the domains.

\section{Conclusion}

The most relevant (sub)domains of HRQoL for patients with COPD were: physical health (fatigue, physical functioning), social health (instrumental support, ability to participate in social roles and activities, companionship, and emotional support), and coping with COPD. The latter is not explicitly covered by any of the existing PROMIS domains, or by the most popular traditional questionnaires that are used to measure HRQoL in COPD. Our results reaffirm what has been pointed out in previous studies [27]: engaging patients in PROM development and evaluation is crucial to ensure content validity. The identified PROMIS domains could form the basis for a CAT measuring HRQoL in COPD patients. We recommend the development of a disease-specific module to be included in the CAT, to capture important HRQoL aspects not covered by the current PROMIS domains. When selecting or developing instruments, we argue that it is important to take into account expert opinion as well as patient experience (see Additional file 1). Therefore, we will conduct interviews with healthcare professionals in a future study. To ensure the cross-cultural relevance and external validity of our findings, we will repeat these interviews (with patients and healthcare professionals) in other countries as well, starting with Canada.

\section{Additional files}

\section{Additional file 1: Outlines the framework we use in developing a CAT to measures HRQoL.}

Additional file 2: Constitutes the interview scheme used to gather data for this study.

Additional file 3: Lists the 16 PROMIS domains (with example items) the patients had to choose from during the card sorting task.

\section{Competing interests}

The authors declare that they have no competing interests.

\section{Authors' contributions}

MP was involved in the design of the study, analysis and interpretation of data, and drafted the manuscript. CB was involved in the design of the study, critically reviewed all aspects of data collection, analysis and interpretation, and revised the manuscript critically for important intellectual content. LL played a key role in data analysis and the interpretation of the data, and revised the manuscript critically for important intellectual content. LG collected the data, and made a contribution to data analysis and revision of the manuscript. SA and OE drafted Additional file 1 and critically reviewed all aspects of the study, including the manuscript. CT was involved in the design of the study, selected PROMIS example items, and critically reviewed all aspects of the study, including the manuscript. JP was involved in the design of the study and the drafting of the manuscript. All authors read and approved the final manuscript.

\section{Acknowledgements}

We thank Mitzi Paap, Bachelor of Arts in English language and culture, for translating the interview scheme. We also thank all patients that participated in this study. This study was supported by grant \#3.4.11.004 from Lung Foundation Netherlands.

\section{Author details}

'Department of Research Methodology, Measurement, and Data-Analysis, Behavioral Sciences, University of Twente, P.O. Box 217, 7500 AE Enschede, The Netherlands. ${ }^{2}$ Department of Psychology, Health \& Technology, Behavioral Sciences, University of Twente, Enschede, The Netherlands. ${ }^{3}$ University of Twente, Enschede, The Netherlands. ${ }^{4}$ Current affiliation: Department of Clinical Psychology, Behavioural and Social Sciences, University of Groningen, Groningen, The Netherlands. ${ }^{5}$ Department of Epidemiology and Biostatistics, The EMGO Institute for Health and Care Research, VU University Medical Center, Amsterdam, The Netherlands. ${ }^{6}$ School of Physical and Occupational Therapy, Faculty of Medicine, McGill University; with concordant appointments at McGill University Health Center's Division of Clinical Epidemiology; and, the Centre de recherche interdisciplinaire en réadaptation, Constance Lethbridge Rehabilitation Center, Montréal, Québec, Canada. ${ }^{7}$ Faculty of Medicine, School of Physical Therapy, McGill University, Montreal, QC, Canada. ${ }^{8}$ Medical School Twente, Medisch Spectrum Twente, Enschede, The Netherlands.

Received: 17 March 2014 Accepted: 19 June 2014

Published: 9 July 2014 


\section{References}

1. Chronic obstructive pulmonary disease (COPD) (Fact Sheet No.315). [http://www.who.int/mediacentre/factsheets/fs315/en/index.html]

2. Nici L, Donner C, Wouters E, Zuwallack R, Ambrosino N, Bourbeau J, Carone M, Celli B, Engelen M, Fahy B, Garvey C, Goldstein R, Gosselink R, Lareau S, Maclntyre N, Maltais F, Morgan M, O'Donnell D, Prefault C, Reardon J, Rochester C, Schols A, Singh S, Troosters T: American thoracic society/ European respiratory society statement on pulmonary rehabilitation. Am J Respir Crit Care Med 2006, 173(12):1390-1413.

3. Pauwels RA, Buist AS, Calverley PMA, Jenkins CR, Hurd SS: Global Strategy for the Diagnosis, Management, and Prevention of Chronic Obstructive Pulmonary Disease. Am J Respir Crit Care Med 2001, 163(5):1256-1276.

4. Cella D: Quality of life: the concept. J Palliat Care 1992, 8(3):8-13.

5. Weldam SW, Schuurmans MJ, Liu R, Lammers JW: Evaluation of Quality of Life instruments for use in COPD care and research: A systematic review. Int J Nurs Stud 2013, 50(5):688-707.

6. Kruyen PM, Emons WHM, Sijtsma K: On the Shortcomings of Shortened Tests: A Literature Review. Int J Test 2013, 13(3):223-248.

7. Kruyen PM, Emons WHM, Sijtsma K: Assessing Individual Change Using Short Tests and Questionnaires. Appl Psychol Meas 2014, 38(3):201-216.

8. Paap MCS, Brouwer D, Glas CAW, Monninkhof EM, Forstreuter B, Pieterse ME, van der Palen J: The St George's Respiratory Questionnaire revisited: a psychometric evaluation. Qual Life Res 2013. [Epub ahead of print].

9. Barclay-Goddard R, Epstein JD, Mayo NE: Response shift: a brief overview and proposed research priorities. Qual Life Res 2009, 18(3):335-346.

10. Ackerman TA: Developments in multidimensional item response theory. Appl Psychol Meas 1996, 20:309-310.

11. Daudey L, Peters JB, Molema J, Dekhuijzen PN, Prins JB, Heijdra YF, Vercoulen $\mathrm{JH}$ : Health status in COPD cannot be measured by the St George's Respiratory Questionnaire alone: an evaluation of the underlying concepts of this questionnaire. Respir Res 2010, 11:98.

12. Computerized Adaptive Testing: Theory and Practice. Edited by Van der Linden WJ, Glas CAW. Dordrecht: Kluwer Academic Publishers; 2000.

13. Embretson SE, Reise S: Item response theory for psychologists. Mahwah, NJ: Erlbaum; 2000

14. Cella D, Yount S, Rothrock N, Gershon R, Cook K, Reeve B, Ader D, Fries JF, Bruce B, Rose M: The Patient-Reported Outcomes Measurement Information System (PROMIS): progress of an NIH Roadmap cooperative group during its first two years. Med Care 2007, 45:S3-S11.

15. Cella D, Riley W, Stone A, Rothrock N, Reeve B, Yount S, Amtmann D, Bode R, Buysse D, Choi S, Cook K, DeVellis R, DeWalt D, Fries JF, Gershon R, Hahn EA, Lai J-S, Pilkonis P, Revicki D, Rose M, Weinfurt K, Hays R: The Patient-Reported Outcomes Measurement Information System (PROMIS) developed and tested its first wave of adult self-reported health outcome item banks: 2005-2008. J Clin Epidemiol 2010, 63:1179-1194.

16. Zeldenryk L, Gray M, Gordon S, Speare R, Hossain M: The use of focus groups to develop a culturally relevant quality of life tool for lymphatic filariasis in Bangladesh. Qual Life Res 2014, 23:299-309.

17. Ferrell BR, Grant MM, Funk B, Otis-Green S, Garcia N: Quality of Life in Breast Cancer Survivors as Identified by Focus Groups. Psycho-Oncology 1997, 6:13-23.

18. Brod M, Stewart AL, Sands L, Walton P: Conceptualization and Measurement of Quality of Life in Dementia: The Dementia Quality of Life Instrument (DQoL). The Gerontologist 1999, 39:25-36.

19. Ronen G, Rosenbaum P, Law M, Streiner D: Health-related quality of life in childhood disorders: A modified focus group technique to involve children. Qual Life Res 2001, 10:71-79.

20. Groenvold M, Petersen MA, Aaronson NK, Arraras Jl, Blazeby JM, Bottomley A, Fayers PM, de Graeff A, Hammerlid E, Kaasa S, Sprangers MAG, Bjorner JB, for the EORTC Quality of Life Group: The development of the EORTC QLQC15-PAL: a shortened questionnaire for cancer patients in palliative care. Eur J Cancer 2006, 42:55-64.

21. Velikova G, Awad N, Coles-Gale R, Wright EP, Brown JM, Selby PJ: The clinical value of quality of life assessment in oncology practice-a qualitative study of patient and physician views. Psycho-Oncology 2008, 17:690-698.

22. Nikolaus S, Bode C, Taal E, van de Laar MA: Which dimensions of fatigue should be measured in patients with rheumatoid arthritis? A Delphi study. Musculoskeletal Care 2012, 10:13-17.

23. Lasch K, Marquis P, Vigneux M, Abetz L, Arnould B, Bayliss M, Crawford B, Rosa K: PRO development: rigorous qualitative research as the crucial foundation. Qual Life Res 2010, 19:1087-1096.
24. Bredart A, Marrel A, Abetz-Webb L, Lasch K, Acquadro C: Interviewing to develop Patient-Reported Outcome (PRO) measures for clinical research: eliciting patients' experience. Health Qual Life Outcomes 2014, 12:15.

25. Patrick D, Burke L, Gwaltney C, Leidy N, Martin M, Molsen E, Ring L: Content validity-establishing and reporting the evidence in newly developed patient-reported outcomes (PRO) instruments for medical product evaluation: ISPOR PRO good research practices task force report: part 1-eliciting concepts for a new PRO instrument. Value Health 2011, 14:967-977.

26. Patrick D, Burke L, Gwaltney C, Leidy N, Martin M, Molsen E, Ring L: Content validity-establishing and reporting the evidence in newly developed patient-reported outcomes (PRO) instruments for medical product evaluation: ISPOR PRO Good Research Practices Task Force report: part 2assessing respondent understanding. Value Health 2011, 14:978-988.

27. Brod M, Tesler L, Christensen T: Qualitative research and content validity: developing best practices based on science and experience. Qual Life Res 2009, 18:1263-1278.

28. Johnson C, Aaronson N, Blazeby JM, Bottomley A, Fayers P, Koller M, Kuliś D, Ramage J, Sprangers M, Velikova G, Young T: EORTC Quality of Life Group Guidelines for Developing Questionnaire Modules. 4th edition. Brussels: European Organisation for Research and Treatment of Cancer; 2011.

29. Kelly MA, Morse JQ, Stover A, Hofkens T, Huisman E, Shulman S, Eisen SV, Becker SJ, Weinfurt K, Boland E, Pilkonis PA: Describing depression: congruence between patient experiences and clinical assessments. Br J Clin Psychol 2011, 50:46-66.

30. Riley WT, Pilkonis P, Cella D: Application of the National Institutes of Health Patient-reported Outcome Measurement Information System (PROMIS) to mental health research. J Ment Health Policy Econ 2011, 14:201-208.

31. Pilkonis PA, Choi SW, Reise SP, Stover AM, Riley WT, Cella D: Item banks for measuring emotional distress from the Patient-Reported Outcomes Measurement Information System (PROMIS(R)): depression, anxiety, and anger. Assessment 2011, 18:263-283.

32. DeWalt DA, Rothrock N, Yount S, Stone AA: Evaluation of item candidates: the PROMIS qualitative item review. Med Care 2007, 45:S12-21.

33. Castel LD, Williams KA, Bosworth HB, Eisen SV, Hahn EA, Irwin DE, Kelly MA, Morse J, Stover A, DeWalt DA, DeVellis RF: Content validity in the PROMIS social-health domain: a qualitative analysis of focus-group data. Qual Life Res 2008, 17:737-749.

34. Irwin DE, Varni JW, Yeatts K, DeWalt DA: Cognitive interviewing methodology in the development of a pediatric item bank: a patient reported outcomes measurement information system (PROMIS) study. Health Qual Life Outcomes 2009, 7:3.

35. Ravens-Sieberer U, Devine J, Bevans K, Riley AW, Moon J, Salsman JM, Forrest CB: Subjective well-being measures for children were developed within the PROMIS project: presentation of first results. J Clin Epidemiol 2014, 67:207-218.

36. Walsh TR, Irwin DE, Meier A, Varni JW, DeWalt DA: The use of focus groups in the development of the PROMIS pediatrics item bank. Qual Life Res 2008, 17:725-735.

37. Terwee CB, Roorda LD, Vet HCW, Dekker J, Westhovens R, Leeuwen J, Cella D, Correia H, Arnold B, Perez B, Boers M: Dutch-Flemish translation of 17 item banks from the Patient-Reported Outcomes Measurement Information System (PROMIS). Qual Life Res 2014, [Epub ahead of print].

38. Ahmed S, Mayo NE, Wood-Dauphinee S, Hanley JA, Cohen SR: Using the Patient Generated Index to evaluate response shift post-stroke. Qual Life Res 2005, 14(10):2247-2257.

39. Corbin J, Strauss A: Grounded theory research: Procedures, canons, and evaluative criteria. Qual Sociol 1990, 13:3-21.

40. Domain Frameworks PROMIS Adult Self-Reported Health. [http://www.nihpromis.org/measures/domainframework1]

41. von Leupoldt A, Kenn K: The psychology of chronic obstructive pulmonary disease. Curr Opin Psychiatry 2013, 26(5):458-463. 410.1097/NCO.1090b1013e328363c328361fc.

42. Di Marco F, Verga M, Reggente M, Maria Casanova F, Santus P, Blasi F, Allegra L, Centanni S: Anxiety and depression in COPD patients: The roles of gender and disease severity. Respir Med 2006, 100(10):1767-1774.

43. Maurer J, Rebbapragada V, Borson S, Goldstein R, Kunik ME, Yohannes AM, Hanania NA: Anxiety and depression in COPD: current understanding, unanswered questions, and research needs. Chest 2008, 134(4):43s-56s. 
44. Zhang MW, Ho RC, Cheung MW, Fu E, Mak A: Prevalence of depressive symptoms in patients with chronic obstructive pulmonary disease: a systematic review, meta-analysis and meta-regression. Gen Hosp Psychiatry 2011, 33(3):217-223.

45. Lou P, Zhu Y, Chen P, Zhang P, Yu J, Zhang N, Chen N, Zhang L, Wu H, Zhao J: Prevalence and correlations with depression, anxiety, and other features in outpatients with chronic obstructive pulmonary disease in China: a cross-sectional case control study. BMC Pulm Med 2012, 12:53.

46. Strang S, Ekberg-Jansson A, Henoch I: Experience of anxiety among patients with severe COPD - A qualitative, in-depth interview study. Palliat Support Care 2013. [Epub ahead of print].

47. Lyness JM, Cox C, Curry J, Conwell Y, King DA, Caine ED: Older age and the underreporting of depressive symptoms. Journa J Am Geriatr Soc 1995, 43(3):216-221.

48. Lindqvist $G$, Hallberg LR: Feelings of guilt due to self-inflicted disease': a grounded theory of suffering from chronic obstructive pulmonary disease (COPD). J Health Psychol 2010, 15(3):456-466.

doi:10.1186/s12955-014-0106-3

Cite this article as: Paap et al.: Identifying key domains of health-related quality of life for patients with Chronic Obstructive Pulmonary Disease: the patient perspective. Health and Quality of Life Outcomes 2014 12:106.

\section{Submit your next manuscript to BioMed Central and take full advantage of:}

- Convenient online submission

- Thorough peer review

- No space constraints or color figure charges

- Immediate publication on acceptance

- Inclusion in PubMed, CAS, Scopus and Google Scholar

- Research which is freely available for redistribution 